\title{
Myocardial contractility indices based on strain imaging
}

\author{
Tazim Merchant ${ }^{1 *}$, Danielle Janosevic ${ }^{1}$, Meghana Jayam¹, Madhavi Kadiyala ${ }^{1,2}$, Simcha Pollack , Jie J Cao ${ }^{1,2}$, \\ Nathaniel Reichek ${ }^{1,2}$
}

From 17th Annual SCMR Scientific Sessions

New Orleans, LA, USA. 16-19 January 2014

\section{Background}

The principal determinants of chronic left ventricular (LV) dysfunction are reduced myocardial contractility and afterload excess due to adverse LV remodeling. To determine the relative contribution of each to a given instance of LV dysfunction, reliable quantitative indices of both myocardial contractility and afterload are needed. At the LV chamber level, ventricular volume and LV pressure can be used in a ventricular elastance model. But at the myocardial level, afterload must be normalized per unit of myocardium, conventionally done using wall stress (WS) calculations, while myocardial function is best characterized as systolic myocardial deformation, or strain (ST). Prior experimental model studies have suggested that the ratio of strain to afterload may be an effective contractility index. However, this has not been evaluated in human disease. We have recently shown that a nongeometric LV end-systolic afterload index $(\mathrm{NGI},=($ end-systolic LV pressure $(\mathrm{P}) \times$ volume $(\mathrm{V})) / \mathrm{LV} \operatorname{mass}(\mathrm{M})$, or PV/M), may be superior to conventional circumferential WS (CWS) as a quantitative measure of afterload at the myocardial level, and correlates more closely than CWS with circumferential ST(CST), Therefore, we evaluated the ratios CST/CWS and CST/PV/ $\mathrm{M}$, as candidate contractility indices in normals $(\mathrm{NL})$ and in patients with nonischemic dilated cardiomyopathy $(\mathrm{CM})$.

\section{Methods}

In NLs ( $\mathrm{n}=39,46 \%$ women, age $54.6+14.6 \mathrm{yrs})$ and $\mathrm{CM}$ ( $\mathrm{n}=35,23 \%$ women, age $50.8+5.0$ yrs $)$ we obtained breathhold volumetric CMR cines, SPAMM tagged cines and cuff systolic blood pressure and derived EF, global circumferential strain(CST) and mean strain rate(CSR),

${ }^{1}$ St. Francis Hospital,Research and Education Foundation, Roslyn, New York, USA

Full list of author information is available at the end of the article using feature-tracking(FT) ST, (TomTec Imaging Systems) and in a subset, HARP ST(Diagnosoft). End-systolic stress(CWS,(Mirsky, Biophys. J.1969)) and PV/M were also determined.

\section{Results}

(Table 1) EF, CST and CSR were markedly reduced in $\mathrm{CM}$ and CWS and PV/M markedly elevated, consistent with afterload excess. However, the CST/CWS and $\mathrm{CST} / \mathrm{PV} / \mathrm{M}$ ratios were also markedly reduced in CM, indicative of contractile depression, with generally strong correlations of these ratios with EF and CSR, particularly in CM (Table 2). In stepwise regression, FT

Table 1

\begin{tabular}{cccc}
\hline FT & $\mathbf{C M}(\mathbf{n}=\mathbf{3 5})$ & $\mathbf{N L}(\mathbf{n}=\mathbf{3 9})$ & $\mathbf{p}$ \\
\hline EF & $27.2 \pm 10.8 \%$ & $58.4 \pm 4.6 \%$ & $<0.0001$ \\
\hline CST & $-10.7 \pm 5.3 \%$ & $-23.9 \pm 4.3 \%$ & $<0.0001$ \\
\hline CSR \%/sec & $-32.1 \pm 14.8 \%$ & $-65.7 \pm 14.9$ & $<0.0001$ \\
\hline CWSx10(3)dyn/cm(2) & $307.6 \pm 9.2$ & $176.2 \pm 42.1$ & $<0.0001$ \\
\hline PV/M mm Hg & $162.6 \pm 8.9$ & $84.4 \pm 8.4$ & $<0.0001$ \\
\hline CST/CWS \%/10(3)dyn/cm(2) & $-0.039 \pm 0.025$ & $-0.145 \pm 0.053$ & $<0.0001$ \\
\hline CST/PV/M & $-0.079 \pm 0.062$ & $-0.301 \pm 0.114$ & $<0.0001$ \\
mmHg & & & \\
\hline HARP & & & $p$ \\
\hline EF & CM $(n=11)$ & $\mathrm{NL}(n=38)$ & $<0.0001$ \\
\hline CST & $-8.4 \pm 2.6$ & $-17.4 \pm 2.3$ & $<0.0001$ \\
\hline CSR \%/sec & $-26.2 \pm 8.0$ & $-47.6 \pm 6.5$ & $<0.0001$ \\
\hline CWSx10(3)dyn/cm(2) & $272.9 \pm 114.0$ & $174.7 \pm 41.6$ & 0.017 \\
\hline PV/M mm Hg & $141.09 \pm 60.5$ & $83.3 \pm 17.3$ & 0.010 \\
\hline CST/CWS \%/10(3)dyn/cm(2) & $-0.034 \pm 0.015$ & $-0.106 \pm 0.032$ & $<0.0001$ \\
\hline CST/PV/M & $-0.071 \pm 0.044$ & $-0.217 \pm 0.052$ & $<0.0001$ \\
mmHg & & & \\
\hline
\end{tabular}


Table 2 Strain/Afterload Ratios Versus EF and Strain Rate

\begin{tabular}{llcc}
\hline FT & $\mathbf{n}$ & Spearman $\mathbf{r}$ & $\mathbf{p}$ \\
\hline CST/CWS vs. EF NL & 39 & -0.51 & 0.0009 \\
\hline CST/PV/M vs. EF NL & 39 & -0.70 & $<0.0001$ \\
\hline CST/CWS vs. EF CM & 35 & -0.87 & $<0.0001$ \\
\hline CST/PV/M vs. EF CM & 35 & -0.88 & $<0.0001$ \\
\hline CST/CWS vs. CSR NL & 39 & 0.68 & $<0.0001$ \\
\hline CST/PV/M vs. CSR NL & 39 & 0.69 & $<0.0001$ \\
\hline CST/CWS vs. CSR CM & 35 & 0.86 & $<0.0001$ \\
\hline CST/PV/M vs. CSR CM & 35 & 0.90 & $<0.0001$ \\
\hline HARP & & & \\
\hline CST/CWS vs. EF NL & 38 & -0.2 & $n s$ \\
\hline CST/PV/M vs. EF NL & 38 & -0.54 & 0.0005 \\
\hline CST/CWS vs. EF CM & 11 & -0.72 & 0.013 \\
\hline CST/PV/M vs. EF CM & 11 & -0.80 & 0.003 \\
\hline CST/CWS vs. CSR NL & 38 & 0.54 & 0.0005 \\
\hline CST/PV/M vs. CSR NL & 38 & 0.52 & 0.0008 \\
\hline CST/CWS vs. CSR CM & 11 & 0.55 & $n$ \\
\hline CST/PV/M vs. CSR CM & 11 & 0.66 & 0.026 \\
\hline
\end{tabular}

$\mathrm{CST} / \mathrm{CWS}$ and CST/PV/M ratios were the principal correlates of LV EF, not absolute afterload. AUCs for FT $\mathrm{CST} / \mathrm{CWS}$ and $\mathrm{CST} / \mathrm{PV} / \mathrm{M}$ ratios against EF exceeded $0.90(\mathrm{p}<0.0001)$.

\section{Conclusions}

Strain/stress and strain/PV/M ratios are promising noninvasive myocardial contractile indices which can depict the contribution of contractile depression to reduced myocardial function. However, demonstration of the sensitivity of these indices to changes in inotropic state are also needed to validate these measures for potential research and clinical applications.

\section{Funding}

St. Francis Research Foundation.

\section{Authors' details}

${ }^{1}$ St. Francis Hospital,Research and Education Foundation, Roslyn, New York, USA. ${ }^{2}$ Cardiology, Stony Brook University, Stony Brook, New York, USA.

Published: 16 January 2014

doi:10.1186/1532-429X-16-S1-P333

Cite this article as: Merchant et al:: Myocardial contractility indices

based on strain imaging. Journal of Cardiovascular Magnetic Resonance 2014 16(Suppl 1):P333.
Submit your next manuscript to BioMed Central and take full advantage of:

- Convenient online submission

- Thorough peer review

- No space constraints or color figure charges

- Immediate publication on acceptance

- Inclusion in PubMed, CAS, Scopus and Google Scholar

- Research which is freely available for redistribution

Submit your manuscript at www.biomedcentral.com/submit 